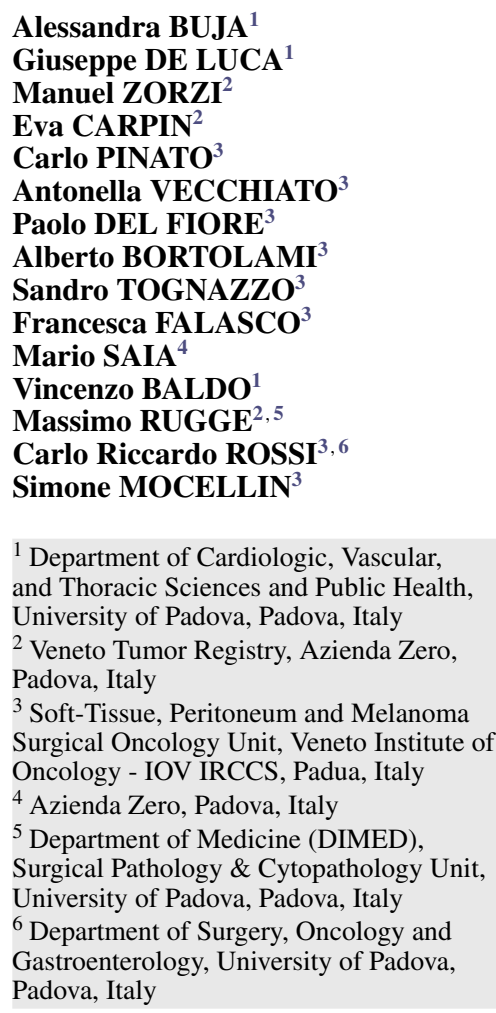

Reprints: Alessandra Buja $<$ alessandra.buja@unipd.it>

\section{Quality management of cutaneous melanoma: impact on short-term outcomes and costs}

\begin{abstract}
Background: Promoting standardization and quality assurance (QA) may guarantee better outcomes for patients and ensure a better allocation of healthcare system resources. Objectives: The present study tested the association between process quality indicators of the clinical pathway for melanoma and both patient short-term mortality and budget utilization. Materials \& Methods: Specific indicators were selected to assess quality of processes in different phases of the pathway as well as the pathway as a whole. Cox regression models were run for each phase to test the association between adherence to the quality indicator and overall mortality. A Tobit regression analysis was used to identify any association between adherence to the quality indicators and total costs over the two years after melanoma was diagnosed. Results: This retrospective cohort study concerned 1,222 incident cases of melanoma in the Veneto Region (north-east of Italy). Adherence to the clinical pathway as a whole was associated with a significant decrease in risk of death $(\mathrm{HR}=0.40 ; 95 \% \mathrm{CI}: 0,19-0,77)$. Adherence to quality processes in the diagnostic phase $(\mathrm{HR}=0.5595 \% \mathrm{CI}$ : 0.31- 0.95) and surgical phase $(\mathrm{HR}=0.3395 \% \mathrm{CI}: 0.16-0.61)$ significantly reduced the hazard risk. Tobit regression revealed a significant increase in overall costs for patients who adhered to the whole pathway in comparison with those who did not $(\beta=2,393.24 ; p=0.013)$. Conclusion: This study suggests that adherence to the quality of management of clinical pathways modifies short-term survival as well as mean cost of care for patients with cutaneous melanoma. Physicians should be encouraged to improve their compliance with clinical care pathways for their melanoma patients, and steadily growing associated costs emphasize the need for policy makers to invest exclusively in treatments of proven efficacy.
\end{abstract}

Key words: quality assurance, quality management, quality indicators, epidemiology, health care costs
$\mathrm{P}$ roviding reproducible, high-quality care is hugely important in oncology. Promoting standardization and quality assurance (QA) in every discipline involved in cancer care should ensure better outcomes for patients, lower costs, and a better allocation of resources from healthcare systems. In fact, improving clinical outcomes through quality control, and optimal resource allocation by means of health technology assessments, makes the QA process a major contributor to a health system's sustainability. The strong correlation between QA and sustainability is particularly important in oncology [1], especially in the light of the growing economic burden of cancer, which is due not only to the rise of disease incidence and survival rates, but also to the growing costs of patient care $[2,3]$. Such a scenario means that policy makers face the difficult task of assuring all patients access to the most effective therapies while simultaneously ensuring the sustainability of healthcare systems as a whole [4].

Cutaneous melanoma $(\mathrm{CM})$ has become a major public health concern due to the steady growth in its incidence rates worldwide (with a 39\% increase between 2006 and 2016) [5], especially in Caucasian populations [6, 7], and the constantly rising associated costs of patient care [810]. In Italy, the incidence of CM has risen in both men and women (from 1.6/100,000 of the male population in 1970 to $21 / 100,000$ in 2015; and from 2/100,000 women in 1970 to $17 / 100,000$ in 2015) [11]. Recent studies have illustrated the heavy burden of this disease in terms of health commitment and expenditure [10, 12]. The Italian Medical Oncological Association (AIOM) has issued national guidelines [13] on the various phases of the clinical management of CMM, from diagnosis to treatment and follow-up, based on the best evidence-based recommendations for optimal patient care. In 2015, the Veneto Regional Authority adapted these guidelines to its regional context (North-East Italy), creating diagnostic, therapeutic and care pathways (DTCPs), aiming to guarantee the best approach to the disease, and the appropriateness of its treatment [14]. In line with recent evidence in the literature $[15,16]$, this document was accompanied by process quality indicators, 
Table 1A. Indicators adopted and their sources [26].

\begin{tabular}{|c|c|c|}
\hline Indicator number & Algorithm of indicator & Source \\
\hline Indicator 1 & Waiting time between biopsy and large excision: $<60$ days (Yes/No) & HRR \\
\hline Indicator 2 & $\begin{array}{l}\text { TNM Stage III patient undergoing CT or MRI or PET scans within } 90 \text { days following the diagnosis } \\
\text { (Yes/No) }\end{array}$ & HRR \\
\hline Indicator 3 & $\begin{array}{l}\text { "pT1, pT2, } \leq 2.0 \mathrm{~mm} \text { thickness with margins }>0.8 \mathrm{~cm} \text { (excluding head of neck and ends) (Yes/No)" or } \\
\text { 3b. "pT3, pT4, }>2 \mathrm{~mm} \text { thick with margins }>1.62 .4 \mathrm{~cm} \text { (excluding the neck and extremities) (Yes/No)" }\end{array}$ & HRR \\
\hline Indicator 4 & Patient undergoing axillary lymphadenectomy with number of lymph nodes removed $>=12(\mathrm{Yes} / \mathrm{No})$ & HRR \\
\hline Indicator 5 & Patient undergoing inguinal lymphadenectomy with number of lymph nodes removed $>=6$ (Yes/No) & HRR \\
\hline Indicator 6 & $\begin{array}{l}\text { Patients undergoing adjuvant medical therapy within } 60 \text { days after lymphadenectomy (Yes/No) } \\
\text { (Except for patients who died within } 60 \text { days from the lymphadenectomy) }\end{array}$ & Adm \\
\hline Indicator 7 & $\begin{array}{l}\text { Stage IV patient, } B R A F \text { mutated, treated with BRAF/MEK inhibitors within } 12 \text { months after diagnosis } \\
\text { (Yes/No) } \\
\text { (Except for patients who died within } 9 \text { months from the diagnosis) }\end{array}$ & HRR \\
\hline Indicator 8 & $\begin{array}{l}\text { Stage IV, non- } B R A F \text { mutated patient treated with immunological check-point inhibitors within } 12 \text { months } \\
\text { of diagnosis (Yes/No) } \\
\text { (Except for patients who died within } 9 \text { months from the diagnosis) }\end{array}$ & HRR \\
\hline Indicator 9 & $\begin{array}{l}\text { Stage IB - IIIC patients with lymph node ultrasound within } 12 \text { months after surgery (Yes/No) } \\
\text { (Except for patients who died within } 3 \text { months from large excision) }\end{array}$ & HRR \\
\hline
\end{tabular}

Table 1B. Indicators calculated according to stage and pathway phase.

\begin{tabular}{|lllll|}
\hline STAGE & Pathway phases & & & Medical therapy \\
\hline & Diagnosis & Surgery & & Follow-up \\
\hline I & 1 & 3 & & 9 (only IB) \\
\hline II & 1 & 3 & 6 & 9 \\
\hline III & $1-2$ & $3-4-5$ & $7-8$ & 9 \\
\hline IV & 1 & 3 & \\
\hline
\end{tabular}

providing clinicians and policy makers with a useful tool to improve the quality of healthcare. As demonstrated in other studies $[17,18]$, such indicators are used to assess the quality of care processes, equity and continuity. Some studies analysed adherence to clinical guidelines in oncology [1922], and the effects of applying the guidelines to certain melanoma outcomes [23], but we still know little about how quality affects patient survival and the average cost of care per patient. It would also be useful to examine how quality affects resource consumption, in order to rationalize expenditure and allocate available resources in the best possible way. Hence, the present study aimed to simultaneously test the association between the quality of the clinical pathway for melanoma and both short-term patient survival and budget utilization.

\section{Materials and methods}

\section{Clinical data}

This study concerns 1,279 cases of CMM diagnosed in 2015 in the seven provinces of the Veneto Region and recorded in the high-resolution Veneto Cancer Registry [24] (until February 2020). Information was collected on patients' characteristics (sex, civil status), diagnostic procedures (e.g.: ultrasonography, CT, MRI, PET), tumour character- istics (e.g.: TNM stage, site, Breslow thickness, mutational status), surgical treatment (excisional skin biopsy, widemargin excision, sentinel lymph node biopsy [SLNB], lymphadenectomy), medical therapy, and follow-up. Our analyses were conducted on 1,222 patients for whom complete information on the TNM stage was available out of the 1,279 cases identified.

\section{Quality indicators}

The working group for the melanoma clinical pathway drew up a list of path and quality indicators to be monitored, with a view to testing the appropriateness of care for melanoma patients. Specific indicators [25] were chosen to assess process quality in the various phases (diagnosis, surgery, medical treatment, follow-up), and in the pathway as a whole. Some indicators were drawn from algorithms used in an administrative database, others using data collected in a more detailed, high-resolution registry (HRR) [14]. Table $1 A$ lists the indicators adopted, their threshold and source. Table $1 B$ shows the distribution of indicators by stage and phase.

\section{Quality of process assessment}

Specific indicators were selected to assess the process quality of the different phases (diagnosis, surgery, medical 
treatment, follow-up) as well as of the pathway as a whole (see table 1B). The measure of quality for a specific phase of the clinical pathway for each specific patient was assessed by calculating the percentage of quality indicators, chosen to monitor that phase, that reached the threshold in that patient. In particular, adherence for a specific phase in each patient was defined when $66 \%$ of the indicators reached the threshold (in all other situations, the patient was defined as non-adherent). Further, the quality of the entire patient pathway was ascertained from the proportion of phases exceeding a predefined threshold (set at $66 \%$ for adherence).

\section{Costs}

This work was calculated from the point of view of the Veneto Region Health Service, only taking the direct costs incurred by the public health authorities into account. The costs were established from the Veneto Regional Authority's official reimbursement tariffs for 2016. Each patient was linked via an anonymous unique identification code to all administrative data regarding their hospital admissions, ambulatory care services, drug prescriptions, emergency department visits, medical device usage, and hospice admissions. We considered the total costs associated with health care services used over two years of follow-up after melanoma was diagnosed. The total cost per-patient were calculated and stratified by stage of disease at diagnosis.

\section{Statistical analysis}

For each phase of the pathway, a Cox proportional-hazards model was run to test the association between overall mortality at two years and adherence to the quality indicators. adjusting all models by sex, age, and stage of disease at diagnosis. Tobit regression analyses were used to identify possible associations between adherence to quality indicators and total costs into two years after melanoma was diagnosed (for each phase and for the pathway as a whole), adjusting for sex, age, and stage of disease at diagnosis.

The R 3.6.2 and SAS 9.4 statistical packages were used for record linkage and all statistical analyses.

\section{Ethical issue}

The data analysis was performed using anonymized aggregate data with no chance of individuals being identifiable. Each patient was linked via an anonymous unique identification code to all administrative data relating to: hospital admissions, ambulatory care services, drug prescriptions, emergency room visits, and medical devices.

Ethical approval was obtained from the Veneto Oncological Institute's Ethics Committee (n $\left.{ }^{\circ} 695 / 20.10 .2016\right)$.

\section{Results}

The 1,222 incident cases of melanoma diagnosed in 2015 and analysed here were distributed as follows: 918 Stage
I, 161 Stage II, 117 Stage III and 26 Stage IV. Mean follow-up time was 1.94 years. The mean age of patients was 58.52 years. Overall survival at two years was $93.7 \%$. The mean total cost per patient was 9,563.94. Table 2 shows the survival and mean per-patient costs according to stage of disease in the first and second years after melanoma was diagnosed, for patients whose management adhered $(n=539)$ or not $(n=683)$ to the whole clinical pathway.

Table 3 shows the association between adherence to quality management for each phase and overall pathways and mortality two years after melanoma was diagnosed. Adherence to the whole pathway was associated with significant reduction in mortality as well as adherence specifically in the diagnostic and surgery phase.

Table 4 shows the impact of adherence on the total costs two years after melanoma was diagnosed, calculated using Tobit regression, adjusted for age, sex and stage of disease at diagnosis. There was a significant increase in costs for overall pathways for patients whose management adhered to the overall pathway $(p=0.013)$.

\section{Discussion}

This study suggests that managing patients according to clinical pathways, with particular regard to diagnostic procedures and surgical procedures, may be associated with improved patient survival, but also with increased mean total costs.

Among the process quality indicators in the surgery phase, we considered the measurement of surgical margins and the number of lymph nodes removed during axillary or inguinal lymphadenectomy. As reported by Sladden et al. in a Cochrane systematic review [26], all melanomas must be surgically removed with an excision margin that depends on the thickness of the primary tumour. There is also evidence that the number of lymph nodes excised positively correlates with the survival of melanoma patients with lymph node metastases [27, 28].

Moreover, the study also demonstrated that the quality of diagnostic processes affected survival and, as suggested by the National Cancer Policy Board [29].

From an economic standpoint, Tobit analysis showed that adherence to the clinical pathway was associated with an overall increase in cost of care for a patient with melanoma, probably because adopting such a pathway favours the use of available resources for managing melanoma patients. Few published studies have examined whether the quality of clinical pathway management affects costs as well as outcomes. Such an approach was taken by Perrier et al., with encouraging results, in their assessment of adherence to practice guidelines in the management of sarcomas [19]; the authors showed that a greater adherence is both less costly and more effective in improving patient survival.

Our findings underscore the importance of promoting the implementation of reproducible, high-quality care in oncology. Quality assurance (QA) guarantees better outcomes for patients and a valuable allocation of resources for healthcare systems. In fact, as suggested by the European Guide for Quality National Cancer Control Programmes [30], this can be important for dealing with the challenges posed by 
Table 2. Survival and mean costs stratified by stage in the first year after diagnosis, for adherents and non-adherents to the clinical pathway as a whole.

\begin{tabular}{|c|c|c|c|c|c|c|c|c|}
\hline \multirow[t]{2}{*}{ Stage at diagnosis } & \multicolumn{4}{|l|}{ Adherents } & \multicolumn{4}{|l|}{ Non-adherents } \\
\hline & No. & $\begin{array}{l}\text { Survival } \\
\text { (No. deceased) }\end{array}$ & $\begin{array}{l}\text { Average } \\
\text { total cost }\end{array}$ & $\begin{array}{l}\text { Mean cost ratio } \\
\text { compared to } \\
\text { Stage I }\end{array}$ & No. & $\begin{array}{l}\text { Survival } \\
\text { (No. Decreased) }\end{array}$ & $\begin{array}{l}\text { Average } \\
\text { total cost }\end{array}$ & $\begin{array}{l}\text { Mean cost } \\
\text { ratio } \\
\text { compared } \\
\text { to Stage I }\end{array}$ \\
\hline \multicolumn{9}{|l|}{ First year } \\
\hline $\mathrm{I}$ & $438(81.26 \%)$ & $99.54 \%(2)$ & $3.706 .95 €$ & 1 & $480(70.28 \%)$ & $98.96 \%(5)$ & $2.913 .43 €$ & 1 \\
\hline II & $87(16.14 \%)$ & $98.85 \%(1)$ & $6.129 .39 €$ & 1.65 & $74(10.83 \%)$ & $90.54 \%(7)$ & $7.154 .15 €$ & 2.46 \\
\hline III & $12(2.23 \%)$ & $100 \%(0)$ & $28.939 .80 €$ & 7.81 & $105(15.37 \%)$ & $91.43 \%(9)$ & $20.150 .59 €$ & 6.92 \\
\hline IV & $2(0.37 \%)$ & $100 \%(0)$ & $19.330 .56 €$ & 5.21 & $24(3.51 \%)$ & $41.67 \%(14)$ & $26.544 .95 €$ & 9.11 \\
\hline TOTAL & $539(100 \%)$ & $99.44 \%(3)$ & $4.717 .70 €$ & & $683(100 \%)$ & $94.88 \%(35)$ & $6.853 .22 €$ & \\
\hline \multicolumn{9}{|l|}{ Second year } \\
\hline I & & $98.63 \%(6)$ & $2.771 .04 €$ & 1 & & $97.71 \%(11)$ & $1.877 .20 €$ & 1 \\
\hline II & & $96.55 \%(3)$ & $4.807 .36 €$ & 1.73 & & $78.38 \%(16)$ & $5.732 .43 €$ & 3.05 \\
\hline III & & $83.33 \%(2)$ & $31.829 .10 €$ & 11.49 & & $80 \%(21)$ & $9.315 .79 €$ & 4.96 \\
\hline IV & & $100 \%(0)$ & $6.776 .15 €$ & 2.45 & & $25 \%(18)$ & $27.636 .82 €$ & 14.72 \\
\hline TOTAL & & $97.96 \%(11)$ & $3.763 .26 €$ & 1.36 & & $90.34 \%(66)$ & $3.775 .35 €$ & 2.01 \\
\hline
\end{tabular}

Table 3. Multivariate Cox regression results (adjusted for sex, age and stage at diagnosis): survival at two years after diagnosis (dependent variables) and adherence to quality management indicators in each phase and during the pathway overall (independent variable).

\begin{tabular}{|llll|}
\hline & HR & 95\% CI & $\boldsymbol{p}$ value \\
\hline Adherence to diagnostic phase & 0.55 & $0.31-0.95$ & 0.040 \\
\hline Adherence to surgery phase & 0.33 & $0.16-0.61$ & $<0.001$ \\
\hline Adherence to medical therapy phase & 0.00 & $0.00-1.59$ & 0.989 \\
\hline Adherence to follow-up phase & 0.75 & $0.32-1.84$ & 0.512 \\
\hline Adherence to the whole pathway & 0.40 & $0.19-0.77$ & 0.009 \\
\hline
\end{tabular}

Table 4. Multivariate Tobit regression analysis (adjusted for sex, age and stage at diagnosis): total costs for entire pathway during two years after diagnosis (dependent variable) and adherence to quality management indicators in each phase and over the pathway overall (independent variable).

\begin{tabular}{|llll|}
\hline & Coefficient & 95\% CI & $p$ value \\
\hline Adherence to diagnostic phase & 1894.21 & $41.63 ; 3746.78$ & 0.045 \\
\hline Adherence to surgery phase & 1679.86 & $-234.43 ; 3594.15$ & 0.085 \\
\hline Adherence to medical therapy phase & 1088.03 & $-51165.33 ; 53341.39$ & 0.967 \\
\hline Adherence to follow-up phase & 404.79 & $-1763.91 ; 2573.48$ & 0.714 \\
\hline Adherence to the whole pathway & 2393.24 & $504.83 ; 4281.66$ & 0.013 \\
\hline
\end{tabular}

technological advances and the changing needs of cancer patients involving the following activities: (1) institutionalization of quality (with careful attention from policymakers as well as clear lines of responsibility and strict accountability mechanisms); (2) systematic implementation of clinical guidelines (as well as screening protocols, accreditation of professionals and facilities, monitoring and auditing schemes); (3) close linkage with a central cancer registry; and finally, (4) the ability to measure results.
A strength of our study lies in its design; this was a population-based (not centre-specific) study based on a whole cohort of consecutive patients in a given territory over a year, which should minimize selection bias. However, we recognize that our study also has some limitations. First, the cost data were derived from healthcare administrations, which do not consider out-of-pocket expenses; nevertheless, the Italian healthcare system exempts cancer patients from any charge, giving them free access to all 
diagnostic procedures and therapies, thus they are unlikely to opt for paid procedures. Second, since the study followup was short, and the majority of patients had a melanoma at initial stages, it was not possible to highlight the impact of medical therapy on outcomes and costs associated with advanced stages. Future analyses, involving more recent cohorts, should include more Stage III and IV patients with longer follow-up, in order to also capture the effectiveness of adjuvant therapy. Thirdly, no information was collected on our patients' comorbidities, therefore differences in cost and survival between subgroups might be partly attributable to different distributions of such comorbidities (due to a different propensity of physicians to handle more complex patients). However, the indicators were calculated (see restriction criteria) only in those patients whose survival was long enough to permit therapy. Finally, further studies are needed to evaluated other indicators, in particular, to capture whether adherence to established clinical pathways in primary melanoma care can result in a more favourable distribution of stage at diagnosis, which has significant clinical value in reducing the outcome of costs.

In conclusion, this study shows how adherence to a good quality clinical pathway for managing cutaneous malignant melanoma improves patient short-term survival and raises the mean per-patient cost of care. Overall, physicians should be encouraged to follow the clinical pathway to care for their patients, while the steadily-rising related costs underscore the need for policymakers to invest exclusively in treatments with confirmed effectiveness.

Disclosures. Conflicts of interest: Funding for this study was provided by CARIPARO, Fondazione Cassa di Risparmio di Padova e Rovigo. This company had no role in the design of the study, the collection, analysis, or interpretation of the data, the writing of the manuscript, or the decision to submit the paper for publication

\section{References}

1. Rossi C, Sommariva A, Bastiaannet E, et al. Quality assurance and sustainability of cancer care: a European network is needed. Eur J Surg Oncol 2018; 44: 383-5.

2. Yabroff KR, Lund J, Kepka D, et al. Economic burden of cancer in the United States: estimates, projections and future research. Cancer Epidemiol Biomark Prev 2011; 20: 2006-14.

3. Bray F, Jemal A, Torre LA, et al. Long-term realism and costeffectiveness: primary prevention in combatting cancer and associated inequalities worldwide. J Natl Cancer Inst 2015; 107: djv273.

4. Specchia ML, La Torre G, Calabrò GE, et al. Disinvestment in cancer care: a survey investigating European countries' opinions and views. Eur J Public Health 2018; 28: 987-92.

5. Global Burden of Disease Cancer Collaboration. Global, regional and national cancer incidence, mortality, years of life lost, years lived with disability, and disability-adjusted life-years for 29 cancer groups, 1990 to 2016: a systematic analysis for the global burden of disease study. JAMA Oncol 2018; 4: 1553-68.

6. Forsea AM, Del Marmol V, de Vries E, et al. Melanoma incidence and mortality in Europe: new estimates, persistent disparities. Br J Dermatol 2012; 167: 1124-30.
7. Guy GP Jr., Thomas CC, Thompson $T$, et al. Vital signs: melanoma incidence and mortality trends and projections - United States, 1982-2030. MMWR Morb Mortal Wkly Rep 2015;64: 591-6.

8. Kandel $M$, Allayous $C$, Dalle $S$, et al. Update of survival and cost of metastatic melanoma with new drugs: estimations from the MelBase cohort. Eur J Cancer 2018; 105: 33-40.

9. Elliott TM, Whiteman DC, Olsen CM, et al. Estimated healthcare costs of melanoma in Australia over 3 years post-diagnosis. Appl Health Econ Health Policy 2017; 15: 805-16.

10. Buja A, Sartor G, Scioni M, et al. Estimation of direct melanomarelated costs by disease stage and by phase of diagnosis and treatment according to clinical guidelines. Acta Derm Venereol 2018;98: 218-24.

11. Rossi S, Crocetti E, Capocaccia R, et al. Estimates of cancer burden in Italy. Tumori 2013;99:416-24.

12. Calabria $S$, Rielli R, Dondi L, Pedrini A. Burden of disease e costi assistenziali integrati dei pazienti affetti da Melanoma Metastatico. Istituto Superiore di Sanità, 2015.

13. AIOM. Linee guida. Melanoma. AIOM, 2014. Available at https://www.aiom.it/melanoma-6/ (Accessed April 20, 2020).

14. PDTA Melanoma working group. Portale Sanità Regione del Veneto. Available at https://salute.regione.veneto.it/web/rov/pdtamelanoma (Accessed February 12, 2020).

15. Mainz J. Defining and classifying clinical indicators for quality improvement. Int J Qual Health Care 2003; 15: 523-30.

16. Mainz J, Hansen A-M, Palshof $T$, et al. National quality measurement using clinical indicators: the Danish National Indicator Project. J Surg Oncol 2009; 99: 500-4.

17. Bilimoria KY, Raval MV, Bentrem DJ, et al. National assessment of melanoma care using formally developed quality indicators. J Clin Oncol 2009; 27: 5445-51

18. Lilford RJ, Brown CA, Nicholl J. Use of process measures to monitor the quality of clinical practice. BN 2007; 335: 648-50.

19. Perrier L, Buja A, Mastrangelo $G$, et al. Clinicians' adherence versus non adherence to practice guidelines in the management of patients with sarcoma: a cost-effectiveness assessment in two European regions. BMC Health Serv Res 2012; 12: 82

20. Ray-Coquard I, Philip T, de Laroche G, et al. Persistence of medical change at implementation of clinical guidelines on medical practice: a controlled study in a cancer network. J Clin Oncol 2005; 23: 4414-23.

21. Blakely A, Comissiong D, Vezeridis $M$, et al. Suboptimal compliance with national comprehensive cancer network melanoma guidelines: who is at risk? Am J Clin Oncol 2017; 41:1.

22. Varey $A H R$, Madronio $C M$, Cust $A E$, et al. Poor adherence to national clinical management guidelines: a population-based, cross-sectional study of the surgical management of melanoma in New South Wales, Australia. Ann Surg Oncol 2017;24: 2080-8

23. Kielhorn $B A$, Jantz JB, Kosten $M S$, et al. Quality improvement in melanoma care: multidisciplinary quality program development and comparison of care before and after implementation. Midwest Surg Assoc 2019;217:527-31

24. Guzzinati $S$, Zorzi $M$, Rossi $C R$, et al. High resolution registry of melanoma and care pathways monitoring in the Veneto Region, Italy. Available at https://www.registrotumoriveneto.it/it/ pubblicazioni/convegni/poster/101-2018/234-high-resolutionregistry-of-melanoma-and-care-pathways-monitoring-in-the-venetoregion-italy (Accessed February 20, 2020).

25. Portale Sanità Regione del Veneto. Aggiornamento del PDTA per pazienti affetti da melanoma. Available at https://salute.regione. veneto.it/c/document_library/get_file? uvid=6fff83 19-b2f5-4b7c-

b 1f6-6c5ab9f57cf5\&groupld=534936 (Accessed February 19, 2020).

26. Sladden M, Balch C, Barzilai DA, et al. Surgical excision margins for primary cutaneous melanoma. Cochrane Database Syst Rev 2009; (4): CD004835. 
27. Rossi CR, Mozzillo N, Maurichi A, et al. Number of excised lymph nodes as a quality assurance measure for lymphadenectomy in melanoma. JAMA Surg 2014; 149:700-6.

28. Rossi CR, Mozzillo N, Maurichi A, et al. The number of excised lymph nodes is associated with survival of melanoma patients with lymph node metastasis. Ann Oncol 2014;25: 240-6.
29. Hewitt M, Simone JV. In: Institute of Medicine (US), National Research Council (US), National Cancer Policy Board, editors. Ensuring Quality Cancer Care. Washington (DC): National Academies Press (US), 1999.

30. Tit A, Jose M, Marjetka J, Lydia G, Meggan H. European guide for quality national cancer control programmes. Ljubljana: National Institute of Public Health, 2015. 